This item was submitted to Loughborough's Research Repository by the author.

Items in Figshare are protected by copyright, with all rights reserved, unless otherwise indicated.

\title{
An explicit model predictive control framework for turbocharged diesel engines
}

PLEASE CITE THE PUBLISHED VERSION

http://dx.doi.org/10.1109/TIE.2013.2279353

PUBLISHER

(C) IEEE

VERSION

AM (Accepted Manuscript)

\section{PUBLISHER STATEMENT}

This work is made available according to the conditions of the Creative Commons Attribution-NonCommercialNoDerivatives 4.0 International (CC BY-NC-ND 4.0) licence. Full details of this licence are available at: https://creativecommons.org/licenses/by-nc-nd/4.0/

\section{LICENCE}

CC BY-NC-ND 4.0

\section{REPOSITORY RECORD}

Zhao, Dezong, Cunjia Liu, Richard Stobart, Jiamei Deng, Edward Winward, and Guangyu Dong. 2017. "An Explicit Model Predictive Control Framework for Turbocharged Diesel Engines". figshare. https://hdl.handle.net/2134/26067. 


\section{An Explicit Model Predictive Control Framework for Turbocharged Diesel Engines}

\begin{abstract}
The turbocharged diesel engine is a typical multiinput multi-output (MIMO) system with strong couplings, actuator constraints, and fast dynamics. This paper addresses the exhaust emissions regulation in turbocharged diesel engines using an explicit model predictive control (EMPC) approach, which allows tracking of the time-varying setpoint values generated by the supervisory level controller while satisfying the actuator constraints. The proposed EMPC framework consists of calibration, engine model identification, controller formulation, and state observer design. The proposed EMPC approach has a low computation requirement and is suitable for implementation in the engine control unit (ECU) on board. The experimental results on a turbocharged $\mathrm{Cat}^{\circledR} \mathrm{C} 6.6$ diesel engine demonstrate that the EMPC controller significantly improves the tracking performance of the exhaust emission variables in comparison with the decoupled single-input single-output (SISO) control methods.
\end{abstract}

Index Terms-Explicit model predictive control, turbocharged diesel engines, exhaust emissions regulation

\section{NOMENCLATURE}

$N \quad$ Engine speed.

$W_{f} \quad$ Engine fueling rate.

$W_{c} \quad$ Compressor air mass flow rate.

$W_{\text {egr }} \quad$ EGR mass flow rate.

$W_{e} \quad$ Engine total mass flow rate.

$W_{t} \quad$ Turbine gas mass flow rate.

$P_{c} \quad$ Compressor power.

$P_{t} \quad$ Turbine power.

$p_{\text {in }} \quad$ Intake manifold pressure.

$p_{\text {exh }} \quad$ Exhaust manifold pressure.

$p_{a} \quad$ Ambient pressure.

$V_{\text {in }} \quad$ Intake manifold volume.

$V_{\text {exh }} \quad$ Exhaust manifold volume.

$T_{\text {in }}$

$T_{\text {exh }}$

$T_{a}$

$F_{1}$

$N_{t c}$

$\lambda_{a}$

$Q_{\text {pilot }}$

$Q_{\text {main }}$

Qtotal

$\theta_{\text {soi }}$

$p_{\text {rail }}$

$R_{\text {fuel }}$

$\rho_{\text {nox }}$

$\theta_{\text {ca } 50}$

$\chi_{e g r}$

$\chi_{v g t}$

$\eta_{m}$

$R_{g}$

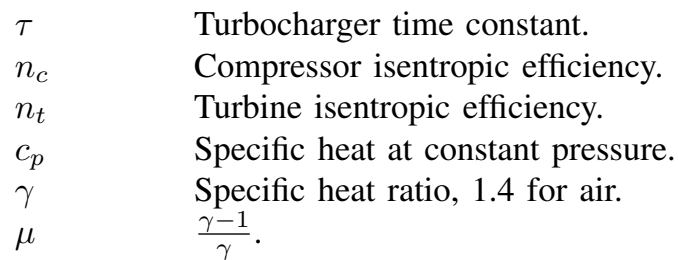

\section{INTRODUCTION}

D IESEL engines are widely used in heavy duty vehicles and off-road applications, due to their merits of high thermal efficiency. However, there is a tradeoff between efficiency and further reduction of exhaust emissions such as nitrogen oxides $\left(\mathrm{NO}_{x}\right)$ and particulate matter (PM). As the increasingly tighter pollution standards are required for vehicles with internal combustion engines (ICE), more exhaust gas regulation systems are fitted to the diesel engines, such as the diesel particulate filter (DPF) and the selective catalytic reduction (SCR) [1], [2]. On a higher level, developing more effective control strategies on the fuel injection and air path subsystem are now essential for improving exhaust emissions [3].

Modern diesel engines are normally equipped with a variable geometry turbocharger (VGT) and exhaust gas recirculation (EGR) valves [4], [5]. Turbocharging the diesel engine reduces fuel consumption, and together with EGR enables a reduction in exhaust emissions, in particular $\mathrm{NO}_{x}$ [6]. VGT and EGR actuators are strongly coupled because they are both exposed to the exhaust gas. They should be well tuned for regulating the intake mass flow for combustion with the desired burnt gas fraction $F_{1}$ to minimize $\mathrm{NO}_{x}$, without violating the air-fuel ratio $\lambda_{a}$ associated with PM generation. Unfortunately, the performance variables, $F_{1}$ and $\lambda_{a}$, are unmeasurable using normal sensors. As a consequence, two intermediate variables, $W_{c}$ and $p_{i n}$ are introduced as the new controlled variables, which are closely related with the previous ones [7]-[9]. The regulation of $F_{1}$ and $\lambda_{a}$ is correspondingly transformed to the control of $W_{c}$ and $p_{i n}$, which are measurable but exhibit nonlinear dynamics due to the coupling between VGT and EGR actuators.

Besides the air path, the exhaust emissions of diesel engines are also massively affected by the inputs on the fuel path, such as the crank angle of start-of-injection $\theta_{\text {soi }}$, fuel rail pressure $p_{\text {rail }}$, fuel ratio $R_{\text {fuel }}$, and dwell time between the pilot fuel injection and main fuel injection [10], [11]. The manipulation of these variables is a challenging task, due to the strong coupling that affects fuel injection. Moreover, a suitable mathematical model of the engine fuel path is lacking. Nowadays, highly sophisticated measurement devices have been developed and implemented on diesel engines, such 


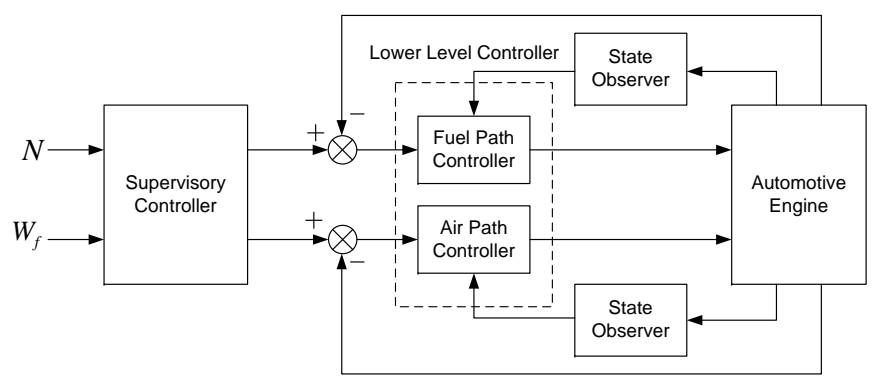

Fig. 1. Hierarchical control structure of the automotive engines

as the air mass flow sensor, boost pressure sensor, and rail pressure sensor. However, on the system control level, most of the fuel path subsystems are feedforward control systems, which implies that the effects of the engine dynamics on exhaust emissions cannot be compensated simply by adjusting the fuel injection [12].

A typical automotive engine controller can be presented in a hierarchical structure, as shown in Fig. 1. The supervisory controller determines the time-varying setpoint values of the lower level controller according to the engine states, in terms of fuel economy [13], exhaust emissions [14], or their weighted cost function [15]. Normally the engine speed $N$ and the fueling rate $W_{f}$ are selected to determine operation points. The lower level controller consists of the fuel path controller and the air path controller, whose main functions are regulating the fuel injection and the fresh air boosting respectively. The lower level controllers regulate the performance variables to their desired setpoint values distributed by the supervisory controller, where the unmeasurable engine states are estimated using state observers.

Focusing on the lower level controllers, most of the commercial ECUs use SISO proportional-integral-differential (PID) controllers in diesel engine air path control, where one regulates the $W_{c}$ by tuning $\chi_{v g t}$, while another regulates the $p_{i n}$ by tuning $\chi_{e g r}$. However, with the increasingly stricter emission standards, it is more difficult for the decoupled SISO methods to meet the setpoint values tracking without consideration of coupling [16]. Therefore, developing control algorithms that can deal with both sets of nonlinear dynamics is required. For the ability to handle the constraints on manipulated variables in MIMO systems, model predictive control (MPC) is one of the most promising control strategies in industrial applications [17]-[23]. Compared with linear quadratic regulators (LQR) that typically optimize the system performance around a given initial state, MPC optimizes at each time step, and results in higher flexibility in dealing with the constraints on inputs, outputs, and states. Several types of MPC methods including generalized predictive control (GPC) [24], nonlinear MPC (NMPC) [7], [25], [26], and adaptive predictive control [27] have been applied in the engine control field. However, the real-time implementation of MPC brings a high computation burden, due to a finite horizon optimal control problem that is solved in each sampling period [28]. Higher computation burden brings higher requirements on the processing power of ECUs, and furthermore, higher

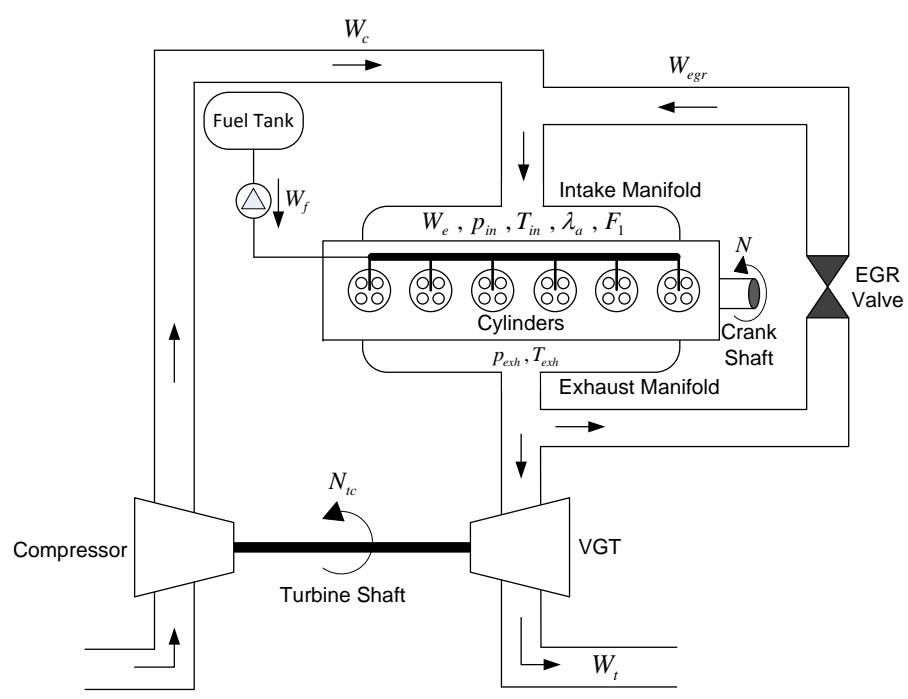

Fig. 2. Turbocharged diesel engine

requirements on the cost. Therefore, high computational cost control methods are unsuited to production diesel engines. Recently, the explicit MPC (EMPC) has attracted interest in engineering with the potential ability to reduce hardware cost and online computation time [29]-[32]. In the EMPC approach, the optimal control laws are pre-computed and read from a look-up table, resulting in reduced computational resource requirements [33]-[35].

In this paper, several aspects of establishing an EMPC framework on diesel engines are proposed. The contributions of this paper mainly focus on the complete procedure in formulating an EMPC controller for exhaust emissions regulation according to the development experience, particularly on the general method of obtaining the multi-linear diesel engine model and building an augmented EMPC controller. Experimental results support the proposed method.

The paper is organized as following. After the introduction in section I, the diesel engine model is described in section II. The EMPC control framework is formulated in section III. The experiment results are stated in section IV. Finally, the conclusions are summarized in section $\mathrm{V}$.

\section{System Description}

The schematic of a turbocharged diesel engine is shown in Fig. 2. The turbocharger consists of the VGT and compressor, where the VGT takes energy from the exhaust gas to power the compressor which is mounted on the same shaft and in turns compresses more fresh air, resulting in higher pressure in the intake manifold. The EGR loop feeds back part of the burnt exhaust gas to the intake manifold to dilute the fresh air, causing lower combustion peak temperature and lowering $\mathrm{NO}_{x}$ concentration. The air and burnt gas are mixed and pumped into the cylinders from the intake manifold. As the piston reaches the top of its compression stroke, fuel is injected into the cylinders and burnt in the now compressed air, producing torque on the crank shaft. The hot burnt exhaust gas is pumped into the exhaust manifold from the cylinders, where part of the exhaust gas flows out of the engine through 


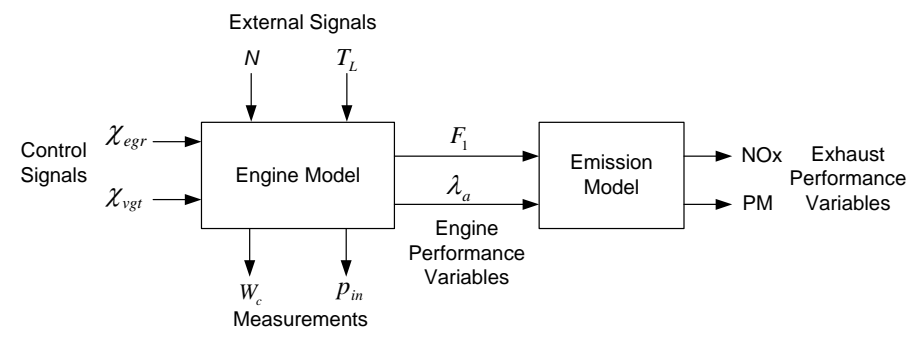

Fig. 3. Signals employed in the air path [5]

the VGT, and the other part is recirculated back to the intake manifold through the EGR valves.

Since the EGR valves and VGT vanes are both in the exhaust gas flow, there is a strong coupling between the EGR flow and VGT flow. The reduction of the pumped fresh air in the intake manifold leads to an increase of PM emissions while a low value of EGR flow fraction results in higher $\mathrm{NO}_{x}$ emissions. The dilemma is known as the $\mathrm{NO}_{x}$-PM tradeoff.

Strong coupling also exists in the fuel path control variables. Generally speaking, the dynamics of the fuel path are often presented by empirical calibration models [36], [37]. Comparing with the air path with relatively slow dynamics due to the turbocharger dynamics and inertia, the fuel path has faster dynamics owing to its more direct influence on the cylinder processes [38], [39].

\section{A. Diesel Engine Air Path}

The signals employed in the air path are shown in Fig. 3 . The exhaust performance variables of the diesel engine are defined as $\mathrm{NO}_{x}$ and $\mathrm{PM}$, while their reduction is achieved by keeping a sufficient large value of $F_{1}$ and $\lambda_{a}$ in the intake manifold, respectively. Therefore, $F_{1}$ and $\lambda_{a}$ are employed as the engine performance variables, defined by

$$
F_{1}=\frac{W_{e g r}}{W_{c}+W_{\text {egr }}} \quad \lambda_{a}=\frac{W_{c}}{W_{f}} .
$$

Precise tracking of $F_{1}$ and $\lambda_{a}$ to their optimal setpoint values $F_{1}^{*}$ and $\lambda_{a}^{*}$ is desired, where $F_{1}^{*}$ and $\lambda_{a}^{*}$ can be obtained using a supervisory controller. In conventional environments, $W_{c}$ and $p_{i n}$ are measured by the compressor air flow sensor and the boost pressure sensor, respectively, to provide the information about the intake gas process [5]. $W_{c}$ and $p_{\text {in }}$ have strong coupling and are regulated by tuning both of the VGT vane and EGR valves.

Ignoring the slow deviation of $T_{i n}$ and $T_{e x h}$, a third-order nonlinear control-oriented air path model is formulated with respect to $p_{i n}, p_{e x h}$, and $P_{c}$ :

$$
\begin{aligned}
\dot{p}_{i n} & =\frac{R_{g} T_{i n}}{V_{i n}}\left(W_{c}+W_{e g r}-W_{e}\right), \\
\dot{p}_{e x h} & =\frac{R_{g} T_{e x h}}{V_{e x h}}\left(W_{e}-W_{e g r}-W_{t}+W_{f}\right), \\
\dot{P}_{c} & =\frac{1}{\tau}\left(\eta_{m} P_{t}-P_{c}\right) .
\end{aligned}
$$

$W_{c}$ is related to $P_{c}$ with

$$
W_{c}=\frac{\eta_{c}}{c_{p} T_{a}} \frac{P_{c}}{p_{i n}^{\mu}-1},
$$

while $P_{t}$ can be expressed by $W_{t}$ :

$$
P_{t}=\eta_{t} c_{p} T_{e x h}\left(1-p_{e x h}^{-\mu}\right) W_{t} .
$$

The mass flow rate through the EGR valves can be obtained by the actuator map given by:

$$
W_{e g r}=\left\{\begin{aligned}
A_{e g r}\left(\chi_{e g r}\right) \frac{p_{e x h}}{\sqrt{R_{g} T_{e x h}}} \Psi\left(\frac{p_{i n}}{p_{e x h}}\right), & \text { if } p_{i n}<p_{e x h} ; \\
0, & \text { if } p_{i n}=p_{e x h} ; \\
A_{\text {egr }}\left(\chi_{e g r}\right) \frac{p_{i n}}{\sqrt{R_{g} T_{i n}}} \Psi\left(\frac{p_{e x h}}{p_{i n}}\right), & \text { if } p_{e x h}<p_{i n} ;
\end{aligned}\right.
$$

where

$$
\Psi\left(\frac{p_{i}}{p_{j}}\right)=\left\{\begin{array}{c}
\gamma^{0.5}\left(\frac{2}{\gamma+1}\right)^{(\gamma+1) /(2(\gamma-1))}, \\
\text { if } \frac{p_{i}}{p_{j}} \leq\left(\frac{2}{\gamma+1}\right)^{\gamma /(\gamma-1)}
\end{array} ;\right.
$$

and $A_{\text {egr }}$ is the EGR effective flow with a quadratic function with respect to $\chi_{e g r}$. The turbine mass flow rate is represented by a modified version of the orifice equation:

$$
W_{t}=A_{v g t}\left(\chi_{v g t}\right) \frac{p_{e x h}}{\sqrt{R_{g} T_{e x h}}} \Phi\left(\frac{p_{a}}{p_{\text {exh }}}, \chi_{v g t}\right),
$$

where $A_{v g t}$ is a quadratic function with respect to $\chi_{v g t}$ and $\Phi\left(\frac{p_{a}}{p_{\text {exh }}}, \chi_{v g t}\right)$ is obtained from a VGT mass flow rate map. The mass flow maps on $W_{t}$ and $W_{e g r}$ together with the efficiency maps on $\eta_{t}$ and $\eta_{c}$ are all generated from calibration tests. The reader can refer to [4] for further details on the air path dynamics.

\section{B. Diesel Engine Fuel Path}

The predominant function of the fuel path is to satisfy the power requirement of the diesel engine under varying loads. The input/output signals employed in the diesel engine fuel path emissions regulation are illustrated in Fig. 4, where the exhaust performance variables are $T_{e x h}, \rho_{\text {nox }}, \theta_{c a 50}$, the control signals are $\theta_{\text {soi }}, p_{\text {rail }}$, and $R_{f u e l}$, and the measurable disturbances are $N$ and $T_{L}$. The unit of $\theta_{\text {soi }}$ is the degrees after top dead center $\left({ }^{\circ} \mathrm{CA}\right.$ ATDC). The exhaust emissions PM is effected by $T_{e x h}$ and $\theta_{c a 50}$ [40]. For ease of understanding. graphical illustrations of the definition of $\theta_{c a 50}$ and the fuel injection sequence in a sampling period are given in Fig. 5(a) Fig. 5(b), respectively. 


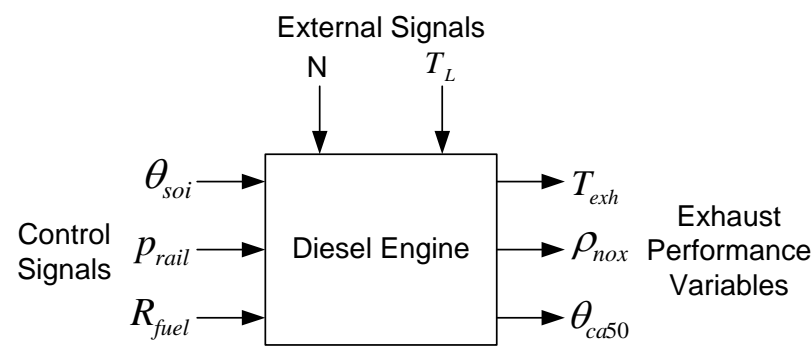

Fig. 4. Signals employed in the fuel path

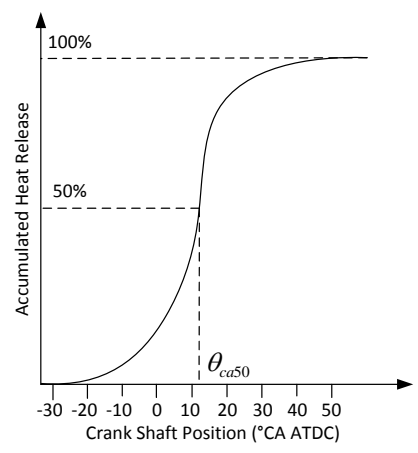

(a) definition of $\theta_{c a 50}$

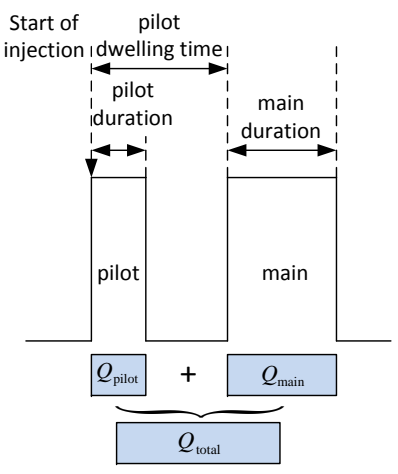

(b) fuel injection sequence
Fig. 5. Demonstration of variables used in the diesel engine fuel path

\section{Linearized Model}

Generally, $W_{f}$ reveals the influence of the load torque $T_{L}$ on the engine. At an engine determined operation point with fixed $N$ and $T_{L}$, the diesel engine air path and fuel path can be modeled as linear systems in form of discrete state space equations:

$$
\left\{\begin{array}{l}
x(k+1)=A x(k)+B u(k), \\
y(k)=C x(k)
\end{array},\right.
$$

where $x \in \mathbb{R}^{n}$ is the state vector, $u \in \mathbb{R}^{m}$ is the input vector, $y \in \mathbb{R}^{p}$ is the output vector, and $(A, B)$ is a controllable pair. Both inputs and outputs of the system are constrained with respect to their maximum and minimum bounds:

$$
u_{\min } \leq u \leq u_{\max }, \quad y_{\min } \leq y \leq y_{\max } .
$$

The coefficient matrices $A, B$, and $C$ are obtained using system identification at the selected operation point. The inputs and outputs of the linearized model for the air path are selected as

$$
\begin{aligned}
& u=\left[\begin{array}{ll}
\chi_{e g r} & \chi_{v g t}
\end{array}\right]^{\mathrm{T}}, \\
& y=\left[\begin{array}{ll}
W_{c} & p_{i n}
\end{array}\right]^{\mathrm{T}},
\end{aligned}
$$

while the inputs and outputs for the fuel path are chosen as

$$
\begin{aligned}
& u=\left[\begin{array}{lll}
\theta_{\text {soi }} & p_{\text {rail }} & R_{\text {fuel }}
\end{array}\right]^{\mathrm{T}} \\
& y=\left[\begin{array}{lll}
T_{\text {exh }} & \rho_{\text {nox }} & \theta_{\text {ca } 50}
\end{array}\right]^{\mathrm{T}} .
\end{aligned}
$$

According to different engine speed and load torque, the engine operation region is segregated into several subzones [29]. The number of subzones depends on the precision of the required identified model. Within each subzone, a linear model is identified at the geometrical central point, as shown in Fig. 6.

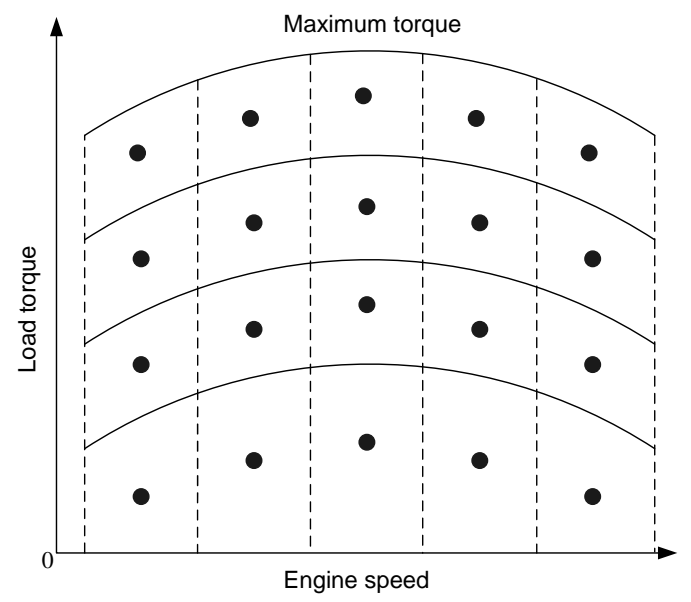

Fig. 6. Segmentation of the engine operation region

\section{EMPC FRAMEWORK DESIGN}

As shown in Fig. 7, the implementation of EMPC can be divided into two stages: offline and online. In the offline stage, the diesel engine model is identified using the calibration data. Based on the identified model, the EMPC control laws are calculated via multi-parametric quadratic programming method and stored in the look-up table within the ECU. In the online stage, the diesel engine is controlled by the pre-computed control law, and the feedback states are estimated via the state observer, fulfilling the closed-loop control function.

\section{A. Calibration and System Identification}

Considering the nonlinear behavior of the diesel engine, it is infeasible to obtain a unified linear model in the engine operation range. A more practical approach is to identify the piecewise affine models in smaller operation ranges.

The calibration data set should cover the operation range of the diesel engine to be tested. System identification is implemented based on the calibration data which are separated into two parts: training data and validation data. A group of candidate models with different orders should be generated from the training data. The one with the highest fitting score in the validation data is selected as the proper linear model in

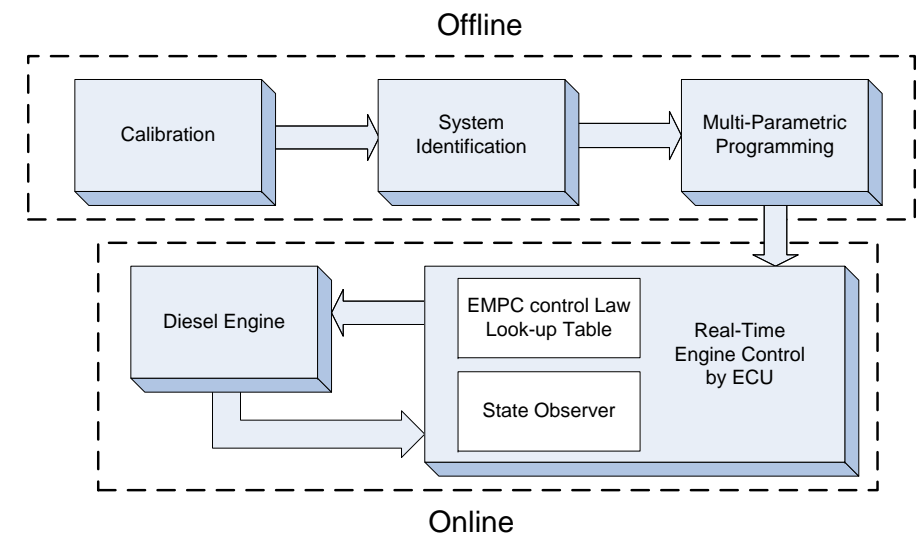

Fig. 7. Implementation procedure of EMPC on the diesel engine 

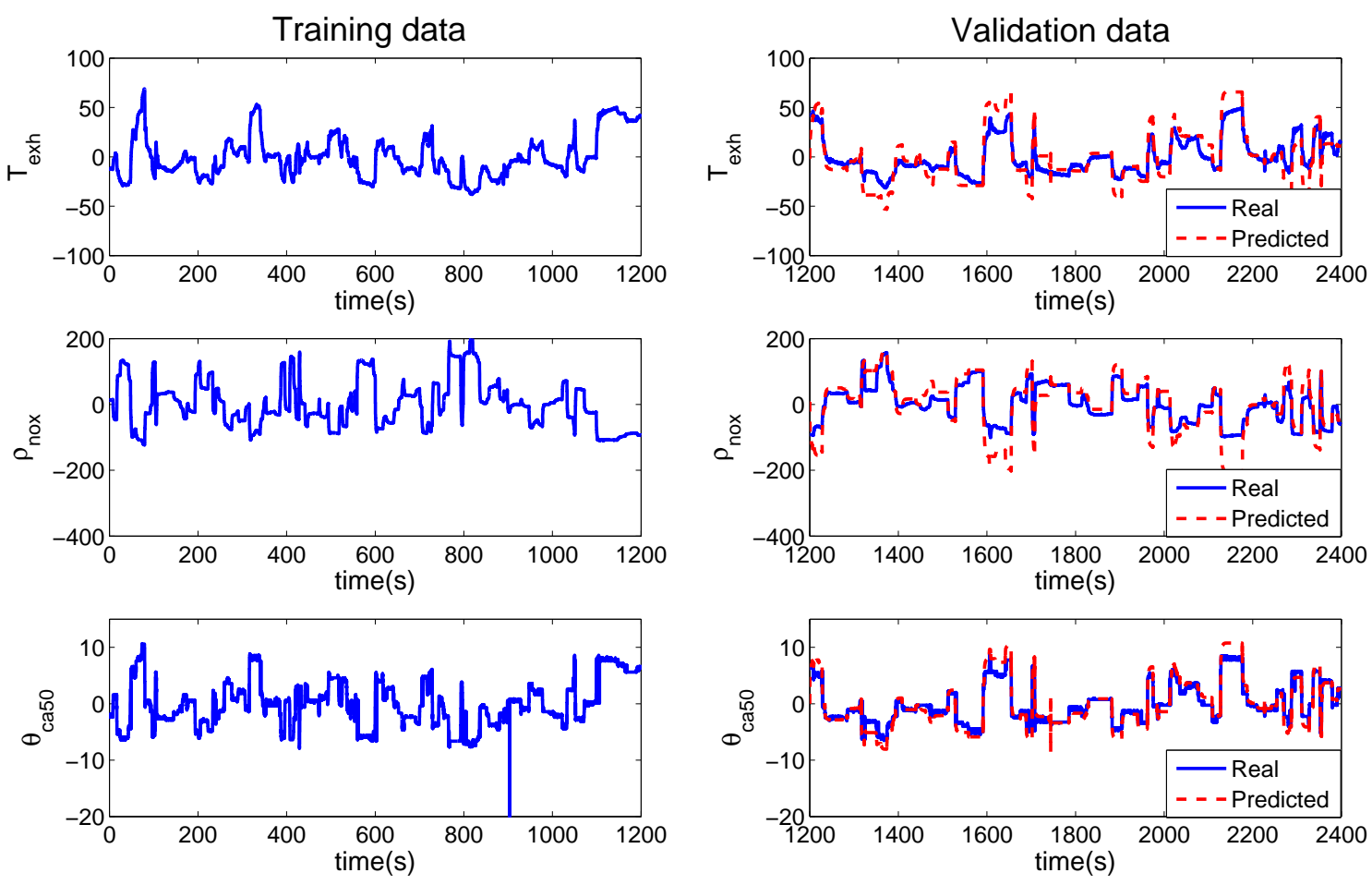

Fig. 8. System identification of the diesel engine fuel path

the assigned zone. Generally speaking, the air path model is ranging from $2^{\text {nd }}$ to $4^{\text {th }}$ order, while the fuel path model is ranging from $3^{\text {rd }}$ to $6^{\text {th }}$ order. As an example, the training data and validation data employed in the fuel path model identification, together with the prediction data using the identified model are illustrated in Fig. 8. The calibration has continued for 40 minutes at the operation point of $1550 \mathrm{rpm}$ and $375 \mathrm{Nm}$, where the first half 20 minutes data are used for training, and the latter half 20 minutes data are used for validation. By comparing the fitting values, a $5^{\text {th }}$-order linear model with the highest score is selected as the fuel path model at the specified engine operation point. The red curves show the predicted data using the identified linear model.

\section{B. EMPC Controller Design}

The EMPC controller described in this subsection adopts the linear MPC technique to achieve tracking of the given output variables.

1) Problem Formulation: The setpoints of output variables are incorporated into the standard EMPC formulation for tracking of time varying reference values. An augmented formulation of (8) including the input dynamics $u(k)=$ $u(k-1)+\Delta u(k)$ and the setpoints of outputs is represented as:

$$
\left\{\begin{array}{c}
\underbrace{\left[\begin{array}{c}
x(k+1) \\
u(k) \\
r(k+1)
\end{array}\right]}_{\tilde{x}_{k+1}}=\underbrace{\left[\begin{array}{ccc}
A & B & 0 \\
0 & I & 0 \\
0 & 0 & I
\end{array}\right]}_{\tilde{A}} \underbrace{\left[\begin{array}{c}
x(k) \\
u(k-1) \\
r(k)
\end{array}\right]}_{\tilde{x}_{k}}+\underbrace{\left[\begin{array}{c}
B \\
I \\
0
\end{array}\right]}_{\tilde{B}} \underbrace{\Delta u(k)}_{\tilde{u}_{k}},
\end{array}\right.
$$

where $\tilde{x}_{k} \in \mathbb{R}^{n+m+p}, \tilde{u}_{k} \in \mathbb{R}^{m}, \tilde{y}_{k} \in \mathbb{R}^{p}$, with $\tilde{C}=$ $[C, 0,-I] ; r(k)$ is the desired setpoint of $y(k)$.

For a generalized system, the system performance index with the initial state $\tilde{x}_{k}$ at time instant $k$ can be specified by a quadratic cost function to be minimized:

$$
\begin{array}{rl}
\min _{U} & J\left(\tilde{x}_{k}, \tilde{U}\right)=\underbrace{\left\|\tilde{x}_{k+H_{p}}\right\|_{P}^{2}}_{J\left(\tilde{x}_{k+H_{p}}\right)}+\sum_{i=0}^{H_{p}-1} \underbrace{\left(\left\|\tilde{x}_{k+i}\right\|_{Q}^{2}+\left\|\tilde{u}_{k+i}\right\|_{R}^{2}\right)}_{J\left(\tilde{x}_{k+i}, \tilde{u}_{k+i}\right)}, \\
\text { s.t. } \tilde{x}_{k+i+1}=\tilde{A} \tilde{x}_{k+i}+\tilde{B} \tilde{u}_{k+i}, & (12 \mathrm{~b}) \\
& \tilde{u}_{\min } \leq \tilde{u}_{k+i} \leq \tilde{u}_{\max }, \quad i=0,1, \ldots, H_{c}-1, \\
\tilde{u}_{k+i}=\tilde{u}_{k+H_{c}-1}, \quad i=H_{c}, \ldots, H_{p}, & (12 \mathrm{c}) \\
& \tilde{y}_{\min } \leq \tilde{y}_{k+i} \leq \tilde{y}_{\max }, \quad i=1, \ldots, H_{p},
\end{array}
$$

where $\|x\|_{S}^{2}=x^{\mathrm{T}} S x ; H_{p}$ and $H_{c}$ are the prediction horizon and control horizon, respectively; $\tilde{x}_{k+i}$ and $\tilde{y}_{k+i}$ denote the predictions of $\tilde{x}$ and $\tilde{y}$ at time $k+i$, made at time $k$, respectively; $\tilde{u}_{k+i}$ is the value of control input $\tilde{u}$ at time $k+i ; \tilde{U}=\left[\begin{array}{lll}\tilde{u}_{k}^{\mathrm{T}} & \ldots, \tilde{u}_{k+H_{p}-1}\end{array}\right]^{\mathrm{T}} \in \mathbb{R}^{m H_{p}}$ is the control sequence within which the optimal control inputs be determined; $\tilde{X}=\left[\tilde{x}_{k+1}^{\mathrm{T}}, \cdots, \tilde{x}_{H_{p}}^{\mathrm{T}}\right]^{\mathrm{T}} \in \mathbb{R}^{(n+m+p) H_{p}}$ is the vector of predicted states; $J\left(\tilde{x}_{k+H_{p}}\right)$ is the terminal penalty function, while $J\left(\tilde{x}_{k+i}, \tilde{u}_{k+i}\right)$ is the stage cost at time $k+i$; From physical point of view, $H_{c} \leq H_{p}$ should be guaranteed. $P=P^{\mathrm{T}}>0, Q=Q^{\mathrm{T}}>0$ and $R=R^{\mathrm{T}}>0$ are assumed.

2) Multi-Parametric Quadratic Programming: The opti(11) mization problem (12) can be converted into a quadratic programming (QP) formation for which fast and numerically reliable algorithms are available. The cost function (12a) is 
re-written in the following quadratic form:

$$
J\left(\tilde{x}_{k}, \tilde{U}\right)=\tilde{X} \bar{Q} \tilde{X}+\tilde{U} \bar{R} \tilde{U},
$$

where the augmented matrices $\bar{Q}$ and $\bar{R}$ are $\bar{Q}=$ $\operatorname{diag}(Q, \cdots, Q, P)$ and $\bar{R}=\operatorname{diag}(R, \cdots, R)$, respectively.

For each element $\tilde{x}_{k+i}$, the evolution of the system (11), i.e. the equality constraint (12b), can be represented by

$$
\tilde{x}_{k+i}=\tilde{A}^{i} \tilde{x}_{k}+\sum_{j=0}^{i-1} \tilde{A}^{j} \tilde{B} \tilde{u}_{k+i-1-j}
$$

for $i=1,2, \ldots, H_{p}$, which means the system states at any time can be expressed in terms of the initial state $\tilde{x}_{k}$ and the inputs vector $\tilde{U}$. Therefore, a matrix expression of the system states evolution can be derived from (14):

$$
\tilde{X}=\bar{A} \tilde{x}_{k}+\bar{B} \tilde{U}
$$

with

$$
\bar{A}=\left[\begin{array}{c}
\tilde{A} \\
\tilde{A}^{2} \\
\vdots \\
\tilde{A}^{H_{c}} \\
\vdots \\
\tilde{A}^{H_{p}}
\end{array}\right] \quad \bar{B}=\left[\begin{array}{cccc}
\tilde{B} & 0 & \cdots & 0 \\
\tilde{A} \tilde{B} & \tilde{B} & \cdots & 0 \\
\vdots & \vdots & \vdots & \vdots \\
\tilde{A}^{H_{c}-1} \tilde{B} & \tilde{A}^{H_{c}-2} \tilde{B} & \cdots & 0 \\
\vdots & \vdots & \vdots & \vdots \\
\tilde{A}^{H_{p}-1} \tilde{B} & \tilde{A}^{H_{p}-2} \tilde{B} & \cdots & \tilde{B}
\end{array}\right] .
$$

Substituting (15) into (13), the optimization problem can be translated into solving the following QP problem :

$$
\begin{aligned}
& J\left(\tilde{x}_{k}, \tilde{U}\right)=\tilde{x}_{k}^{\mathrm{T}} Y \tilde{x}_{k}+\min _{\tilde{U}}\left\{\tilde{U}^{\mathrm{T}} H \tilde{U}+2 \tilde{x}_{k}^{\mathrm{T}} F \tilde{U}\right\}, \\
& \text { s.t. } \quad G \tilde{U} \leq W+E \tilde{x}_{k},
\end{aligned}
$$

where $Y=\bar{A}^{\mathrm{T}} \bar{Q} \bar{A}, H=\bar{B}^{\mathrm{T}} \bar{Q} \bar{B}+\bar{R}$, and $F=\bar{A}^{\mathrm{T}} \bar{Q} \bar{B}$. The matrices $G, W$, and $E$ can be obtained from the constraints (12c) and (12e). The reader can refer to [32] for more details.

Introducing $z \triangleq \tilde{U}+H^{-1} F^{\mathrm{T}} \tilde{x}_{k} \in \mathbb{R}^{m H_{p}}$, the optimization problem (17) can be rewritten as

$$
\begin{gathered}
J_{z}\left(\tilde{x}_{k}, \tilde{U}\right)=\min _{z} z^{\mathrm{T}} H z, \\
\text { s.t. } \quad G z \leq W+S \tilde{x}_{k},
\end{gathered}
$$

where $S \triangleq E+G H^{-1} F^{\mathrm{T}}$, and $J_{z}\left(\tilde{x}_{k}, \tilde{U}\right)=J\left(\tilde{x}_{k}, \tilde{U}\right)-$ $\frac{1}{2} \tilde{x}_{k}^{\mathrm{T}}\left(Y-F H^{-1} F^{\mathrm{T}}\right) \tilde{x}_{k}$. The QP problem (18) can be solved by applying the Karush-Kuhn-Tucker (KKT) optimality conditions [41]:

$$
\begin{aligned}
H z+G^{\mathrm{T}} & =0, \\
\lambda_{i}\left(G_{i} z-W_{i}-S_{i} \tilde{x}_{k}\right) & =0, \quad i=1, \ldots, q, \\
\lambda & \geq 0, \\
G z-W-S \tilde{x}_{k} & \leq 0,
\end{aligned}
$$

where $\lambda \in \mathbb{R}^{q}$ denotes the Lagrange multipliers, and $q$ is the number of inequalities in (18b). The subscript $i$ denotes the $i$-th row of the corresponding matrix.

Let $z^{*}\left(\tilde{x}_{k}\right)$ be the optimal solution to (18) for a given $\tilde{x}_{k}$, the constraint (19b) is called active if $G_{i} z^{*}\left(\tilde{x}_{k}\right)-W_{i}-S_{i} \tilde{x}_{k}=0$ is held. Accordingly, the matrices on the corresponding rows are denoted as $\tilde{G}, \tilde{W}$, and $\tilde{S}$, respectively. Substituting (19b) into (19a), the active Lagrange multiplier $\tilde{\lambda}$ is solved as:

$$
\tilde{\lambda}=-\left(\tilde{G} H^{-1} \tilde{G}^{\mathrm{T}}\right)^{-1}\left(\tilde{W}+\tilde{S} \tilde{x}_{k}\right) .
$$

Substituting (20) into (19a) yields

$$
z=H^{-1} \tilde{G}^{\mathrm{T}}\left(\tilde{G} H^{-1} \tilde{G}^{\mathrm{T}}\right)^{-1}\left(\tilde{W}+\tilde{S} \tilde{x}_{k}\right) .
$$

It is clear from (20) and (21) that $\tilde{\lambda}$ and $z$ are affine functions of $\tilde{x}_{k}$. Substituting (20) and (21) into (19c) and (19d), the region satisfying the constraints can be determined by

$$
\begin{aligned}
-\left(\tilde{G} H^{-1} \tilde{G}^{\mathrm{T}}\right)^{-1}\left(\tilde{W}+\tilde{S} \tilde{x}_{k}\right) & \geq 0, \\
G H^{-1}\left(\tilde{G} H^{-1} \tilde{G}^{\mathrm{T}}\right)^{-1}\left(\tilde{W}+\tilde{S} \tilde{x}_{k}\right) & \leq W+S \tilde{x}_{k} .
\end{aligned}
$$

After removing redundant constraints, (22) describes a polyhedron in the $\tilde{x}_{k}$-space, denoted as the critical region $C R_{0}$, which is represented by

$$
C R_{0}=\left\{\tilde{x}_{k} \mid D \tilde{x}_{k} \leq d, D \in \mathbb{R}^{N_{c} \times(n+m+p)}, d \in \mathbb{R}^{N_{c}}\right\},
$$

where $N_{c}=\operatorname{dim}(d)$ is the total number of inequalities in $D \tilde{x}_{k} \leq d$, which is translated from the constraint (17b). A similar method is also used on dividing the rest of the region:

$$
R_{\text {rest }}=\left\{\tilde{x}_{k} \mid D \tilde{x}_{k} \geq d\right\}
$$

As shown in [33], the optimal EMPC control law is a continuous piecewise affine function of $\tilde{x}_{k}$ on each divided region:

$$
\tilde{U}^{*}\left(\tilde{x}_{k}\right)=f_{j} \tilde{x}_{k}+g_{j}, \quad j=1, \ldots, N_{j},
$$

where $N_{j}$ is the number of polyhedral sets defined by (23) and (24).

3) Implementation: In the offline stage, the optimal EMPC control laws are computed explicitly. The multi-parametric QP solver in polyhedral sets partition is briefly summarized as Algorithm 1.

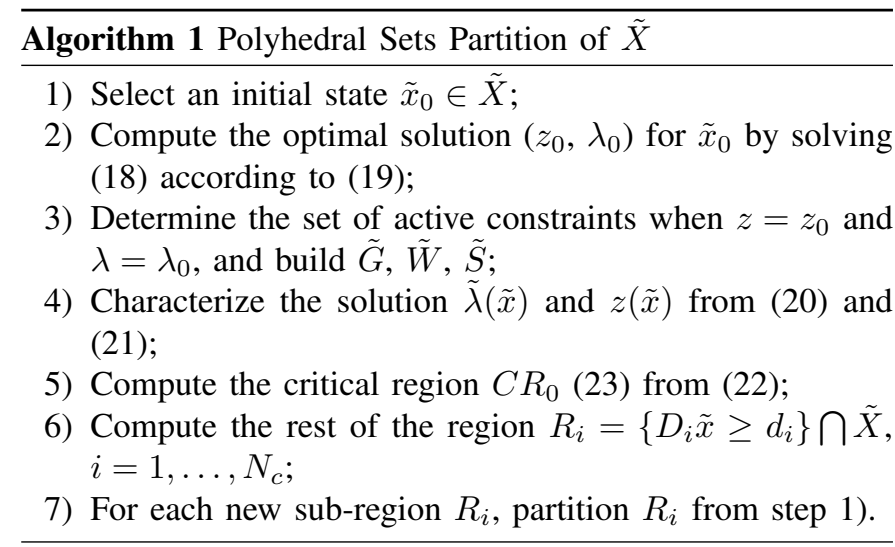

Once the multi-parametric QP problem is solved offline, the EMPC control law (25) is available explicitly. Only the first component of the vector $\tilde{U}^{*}\left(\tilde{x}_{k}\right)$ be applied:

$$
\tilde{u}_{k}=[I, 0, \ldots, 0] \tilde{U}^{*}\left(\tilde{x}_{k}\right) .
$$

The open-source MPT toolbox ${ }^{1}$ based on MATLAB is used to calculate the linear MPC law. On the next step, $\tilde{U}^{*}\left(\tilde{x}_{k+1}\right)$

\footnotetext{
${ }^{1}$ The MPT toolbox is available at http://control.ee.ethz.ch/ mpt/.
} 


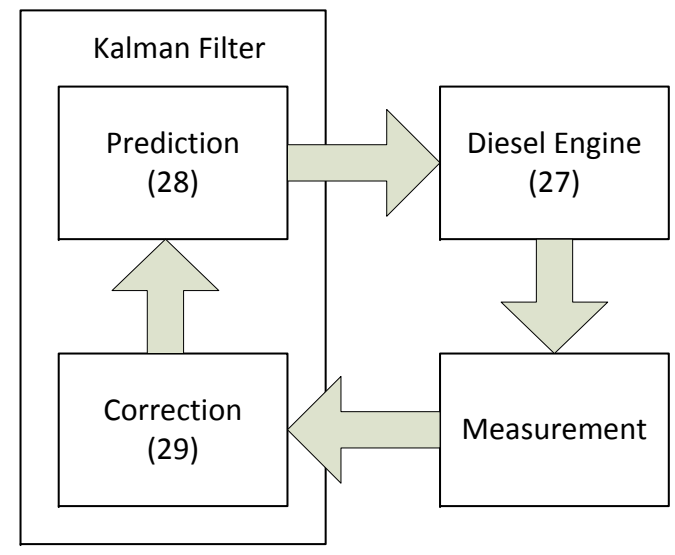

Fig. 9. Workflow of the Kalman filter

is found in the pre-calculated look-up table again, and $\tilde{u}_{k+1}$ is updated accordingly. There are several quick search methods, such as the sequential search, binary search tree, and traverse search tree, that can be used in searching EMPC control laws from the look-up tables [42]. It shares the same function as the normal MPC method, but results in lower hardware cost and reduced online computation resources.

A switched EMPC control scheme is adopted in the realtime control. The identified model of each subzone and the pre-computed control laws are stored in look-up tables. Each subzone may have an identified model with a different order. Accordingly, the designed EMPC in this subzone would have the matched dimension to deal with the plant model. By online identification of the engine speed and the load torque, the EMPC controller in the corresponding subzone would be enabled.

The main advantage of using the EMPC as the engine controller is the ability to handle the control and output constraints, so that the exhaust emissions of the diesel engine can be retained in a reasonable range without violating the practical limits of actuators.

\section{State Estimation}

In this subsection, a Kalman filter is selected for state estimation. The Kalman filter is considered to be the the optimal recursive data processing algorithm, with the highest efficiency across a range of engineering applications [43][45]. Kalman filter uses the state space equation and recursive method to observe the states, and has no requirements on the smooth or time invariant characteristics of the signal. Without loss of generality, considering the diesel engine disturbed by Gaussian white noises, which are represented by the process error $v(k)$ and the measurement error $w(k)$, the augmented system model (11) is transformed to

$$
\left\{\begin{array}{l}
\tilde{x}_{k+1}=\tilde{A} \tilde{x}_{k}+\tilde{B} \tilde{u}_{k}+v(k) \\
\tilde{y}_{k}=\tilde{C} \tilde{x}_{k}+w(k)
\end{array},\right.
$$

where $v(k)$ and $w(k)$ are independent, and hold the covariance of $Q_{v}$ and $R_{w}$, respectively.

The Kalman filter is composed of two sequential steps: prediction and correction. In the prediction step, the prediction of the states are

$$
\hat{\tilde{x}}_{k+1 \mid k}=\tilde{A} \hat{\tilde{x}}_{k \mid k}+\tilde{B} \tilde{u}_{k},
$$

where $\hat{\tilde{x}}_{k+1 \mid k}$ and $\hat{\tilde{x}}_{k \mid k}$ are the estimates of $\tilde{x}_{k+1}$ and $\tilde{x}_{k}$ by the given output sequence of $\left[\tilde{y}_{k}, \tilde{y}_{k-1}, \cdots\right]$, respectively. In the correction step, the updated estimate of $\tilde{x}_{k+1}$ is obtained by

$$
\hat{\tilde{x}}_{k+1 \mid k+1}=\hat{\tilde{x}}_{k+1 \mid k}+\Delta \tilde{x}_{k+1},
$$

where

$$
\begin{aligned}
\Delta \tilde{x}_{k+1} & =K_{k+1} \Delta \tilde{y}_{k+1}, \\
K_{k+1} & =P_{k+1 \mid k} \tilde{C}\left(\tilde{C} P_{k+1 \mid k} \tilde{C}^{\mathrm{T}}\right)^{-1}, \\
\Delta \tilde{y}_{k+1} & =\tilde{y}_{k+1}-\tilde{C} \hat{\tilde{x}}_{k+1 \mid k}, \\
P_{k+1 \mid k} & =\tilde{A} P_{k \mid k} \tilde{A}^{\mathrm{T}}+Q_{v}, \\
P_{k \mid k} & =E\left(\left(\tilde{x}_{k}-\hat{\tilde{x}}_{k \mid k}\right)\left(\tilde{x}_{k}-\hat{\tilde{x}}_{k \mid k}\right)^{\mathrm{T}}\right) .
\end{aligned}
$$

Finally, $P_{k+1 \mid k+1}$ is updated:

$$
P_{k+1 \mid k+1}=P_{k+1 \mid k}-K_{k+1} \tilde{C} P_{k+1 \mid k} \tilde{C}^{\mathrm{T}} K_{k+1}^{\mathrm{T}} .
$$

In the diesel engine model, the covariance matrices of the process noise and measurement noise are specified as $Q_{v}=$ $\operatorname{diag}\left[Q_{1}^{a}, Q_{2}^{a}\right]$ and $R_{w}=\operatorname{diag}\left[R_{1}^{a}, R_{2}^{a}\right]$ in the air path control system, respectively; or $Q_{v}=\operatorname{diag}\left[Q_{1}^{f}, Q_{2}^{f}, Q_{3}^{f}\right]$ and $R_{w}=$ $\operatorname{diag}\left[R_{1}^{f}, R_{2}^{f}, R_{3}^{f}\right]$ in the fuel path control system, respectively. The workflow of the Kalman filter is illustrated in Fig. 9.

\section{EXPERIMENTAL RESUlTS}

The performance of the proposed control method is evaluated in test-cell experiments. Air path tests and fuel path tests are implemented separately. In the air path test, a comparison between an EMPC scheme and a valves-fixed control scheme is made. In the fuel path test, a comparison of an EMPC scheme and a embedded ECU control scheme is demonstrated.

\section{A. Experiment Setup}

The investigated engine is a $\mathrm{Cat}^{\circledR}$ C6.6 ACERT $^{\mathrm{TM}}$ heavyduty off-highway engine. The engine is a 6 -cylinder, 6.6 -liter engine equipped with a common rail fuel system. The engine calibration used for this work produces up to $159 \mathrm{~kW}$ at rated speed of $2200 \mathrm{rpm}$ with peak torque of $920 \mathrm{Nm}$ at $1400 \mathrm{rpm}$. The engine has been modified with a high pressure loop EGR and a Honeywell servo-actuated twin-stage VGT. The engine is fully instrumented to measure air, fuel and cooling system pressure, temperatures, and flow rates. Emissions data is gathered principally from AVL 415 smoke meter, AVL 439 opacity meter, and a Horiba 9100 exhaust gas analyzer measuring $\mathrm{NO}_{x}, \mathrm{CO}_{2}$, hydrocarbons, and oxygen.

The engine is equipped with a CP Engineering Cadet V14 dynamometer control system coupled to a Froude AG400HS eddy current dynamometer, which are used to manage the engine speed and load torque. The air path control law is implemented by $\mathrm{xPC}$, which communicates with the ECU via CAN protocol. The fuel path control system has been developed using FPGA-centric hardware components. The 


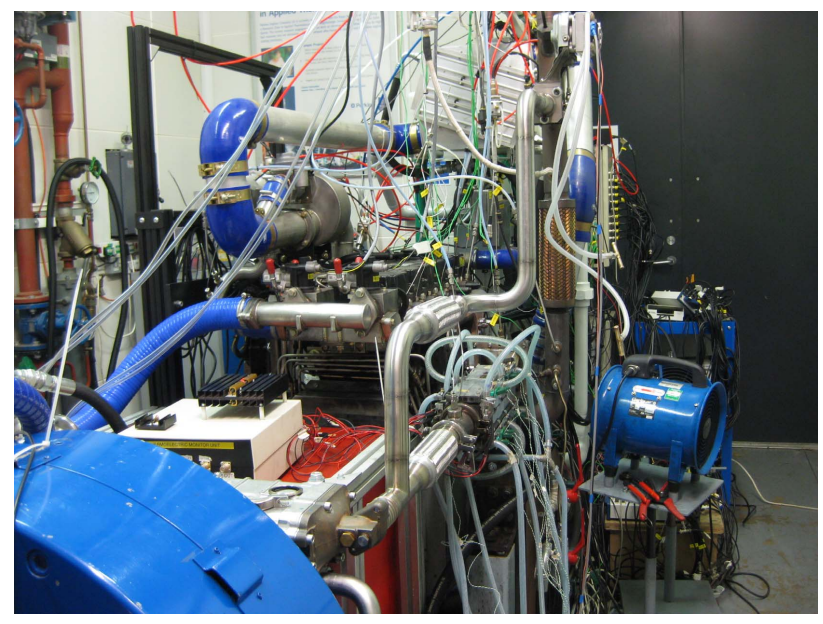

(a) turbocharged diesel engine

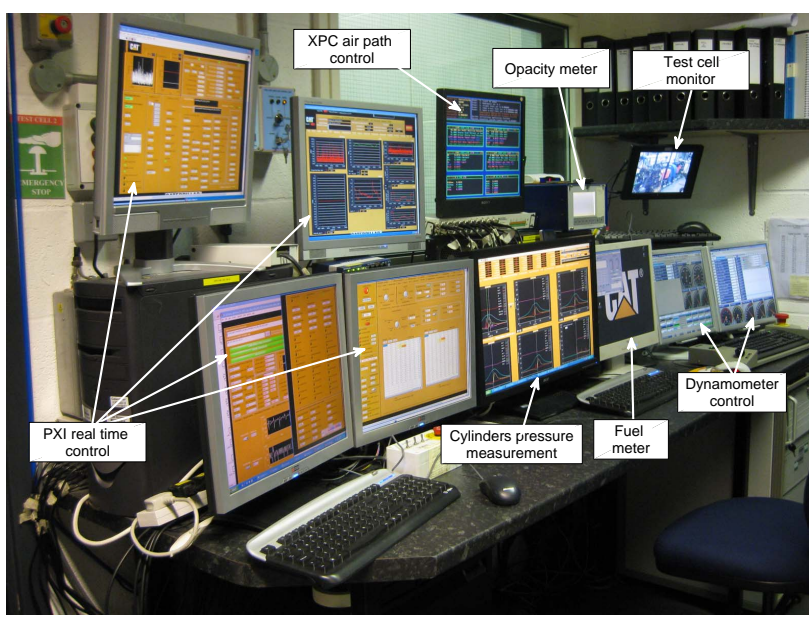

(b) operation platform

Fig. 10. The turbocharged diesel engine and its operation platform

control code of the air path and fuel path are both developed based on Labview 8.5. The key devices in the fuel path control hardware include a PXI-1042Q chassis with a PXI-8106 embedded controller, and three Drivven Diesel Injector Driver Modules which slot into an NI-9151 C-series I/O expansion chassis. Fig. 10 shows the turbocharged diesel engine and its operation platform. The updated performance of PXI real-time control, xPC air path control, and dynamometer control can be observed on the screens. PM and fueling rate are measured by an opacity meter and a fuel meter, respectively, and are both displayed on the screens.

\section{B. Air Path Control Performance Evaluation}

In air path control tests, the commanded engine speed is $1550 \mathrm{rpm}$, while the load torque changes from $375 \mathrm{Nm}$ to $475 \mathrm{Nm}$ during a ramp time, $t_{\text {ramp }}$. The two selected operation points are both located in a subzone, which means the same identified model is used. To verify the EMPC controller performance under different dynamics, $t_{\text {ramp }}$ values are set as $10 \mathrm{~s}$ and $2 \mathrm{~s}$, respectively. The sampling period of the ECU is $0.1 \mathrm{~s}$. The setpoint value of $W_{c}$ changes from $8 \mathrm{~kg} / \mathrm{min}$ to $9.5 \mathrm{~kg} / \mathrm{min}$ with the ramping change of the load torque, while the setpoint value of $p_{\text {in }}$ changes from $162 \mathrm{kPa}$ to $190 \mathrm{kPa}$. The constraints on the inputs $u=\left[\begin{array}{ll}\chi_{e g r} & \chi_{v g t}\end{array}\right]^{\mathrm{T}}$ are defined as

$$
u_{\min }=\left[\begin{array}{c}
5 \% \\
45 \%
\end{array}\right], \quad u_{\max }=\left[\begin{array}{l}
15 \% \\
65 \%
\end{array}\right] .
$$

The prediction horizon and control horizon are set as $H_{p}=8$, $H_{c}=2$, respectively. The fuel path input variables are fixed at

$$
\left[\begin{array}{c}
\theta_{\text {soi }} \\
p_{\text {rail }} \\
R_{\text {fuel }}
\end{array}\right]=\left[\begin{array}{c}
3{ }^{\circ} \mathrm{CA} \mathrm{ATDC} \\
75 \mathrm{kPa} \\
80 \%
\end{array}\right] .
$$

The air path control performance evaluation with $t_{\text {ramp }}=$ $10 \mathrm{~s}$ is given in Fig. 11, where the engine operation condition is illustrated in Fig. 11(a). Both of the valves-fixed control mode and the proposed EMPC control method are tested. In the valves-fixed control mode, the air path dynamics behave as an open-loop control system.

Fig. 11(b) and Fig. 11(c) shows a clear improvement of the transient dynamics of the EMPC controller over the fixed control mode. This is because the EMPC is a MIMO control method which considers both the internal plant coupling and actuator constraints. In the fixed control mode, $\chi_{v g t}$ is kept at $55 \%$ by means of a single loop PID controller, and the $\chi_{\text {egr }}$ is held at $10 \%$. As a result of the open-loop control, the transient performance of the air path is slow and the steady state error is high. It is clear that the tracking performance on the air path is faster and more accurate using the EMPC controller, for the optimal control laws can be selected from pre-calculated solutions quickly. The oscillation is due to the noise produced in the VGT and EGR actuators.

Fig. 11(d) shows the tuning process of $\chi_{v g t}$ and $\chi_{e g r}$ according to the variations of engine operation points. With the increasing setting values of $W_{c}$ and $p_{i n}, \chi_{v g t}$ increases and $\chi_{\text {egr }}$ decreases, which means more fresh air is added and less exhaust gas is recirculated, in order to meet a higher $\lambda_{a}$. With the decreasing setting values of $W_{c}$ and $p_{i n}, \chi_{v g t}$ decreases and $\chi_{\text {egr }}$ increases, since less fresh air and more recirculated exhaust gas are required.

In the fast dynamics test, the engine operation condition is illustrated in Fig. 12(a). In the results given in Fig. 12(b) and Fig. 12(c), the EMPC method also shows superior performance compared with the fixed control mode. The corresponding inputs are illustrated in Fig. 12(d), where $\chi_{\text {egr }}$ touched both of the upper limit and lower limit, which reveals the input constraints are active in this test environment. In practice, $u_{\max }$ and $u_{\min }$ are set according to industrial requirements and safety risk assessments. These considerations imply that the input constraints would be activated only under some special test conditions.

\section{Fuel Path Control Performance Evaluation}

In fuel path control tests, the torque changes with the ramping time of $5 \mathrm{~s}$, while the other test environment parameters 

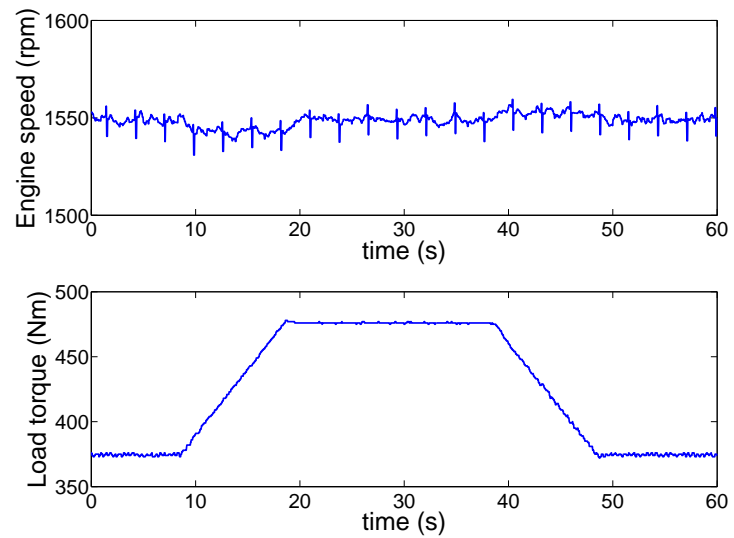

(a) Engine operation condition

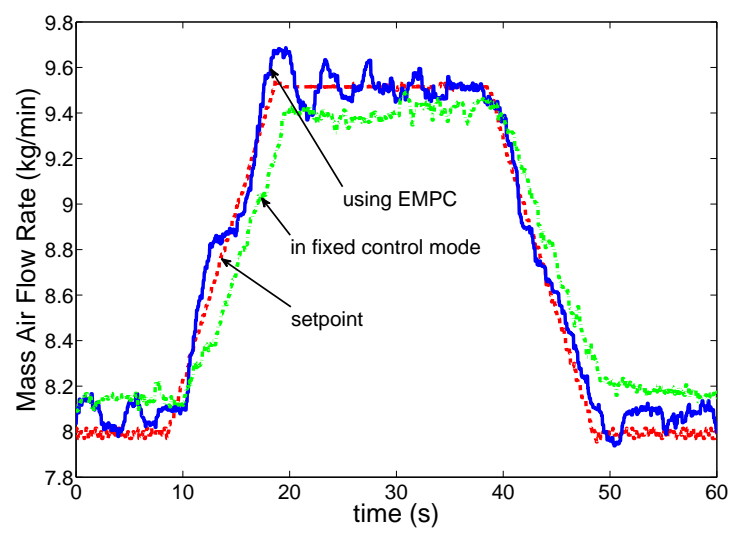

(b) $W_{c}$

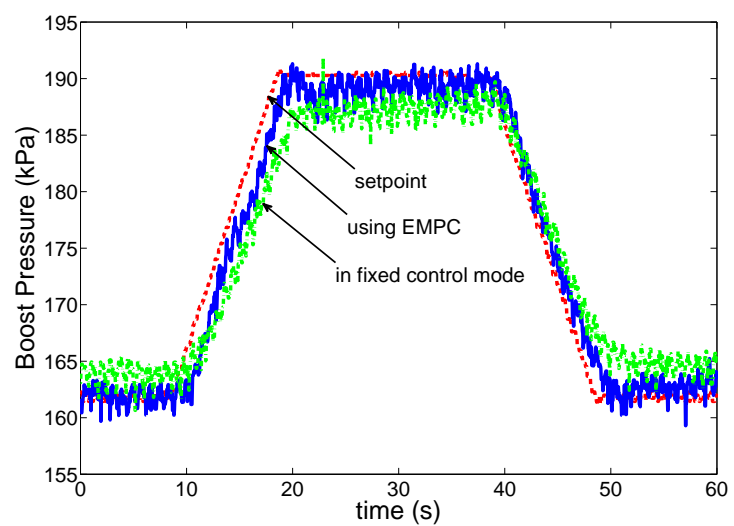

(c) $p_{\text {in }}$
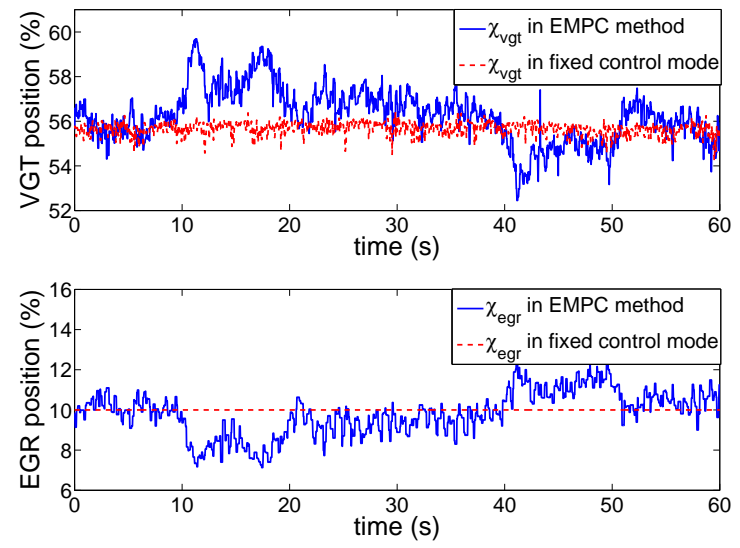

(d) Valves position

Fig. 11. Diesel engine air path control performance evaluation with $t_{r a m p}=$ $10 \mathrm{~s}$
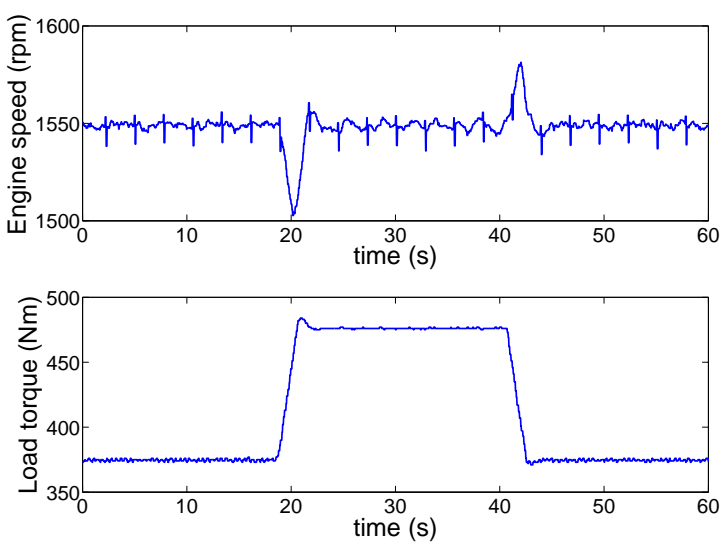

(a) Engine operation condition

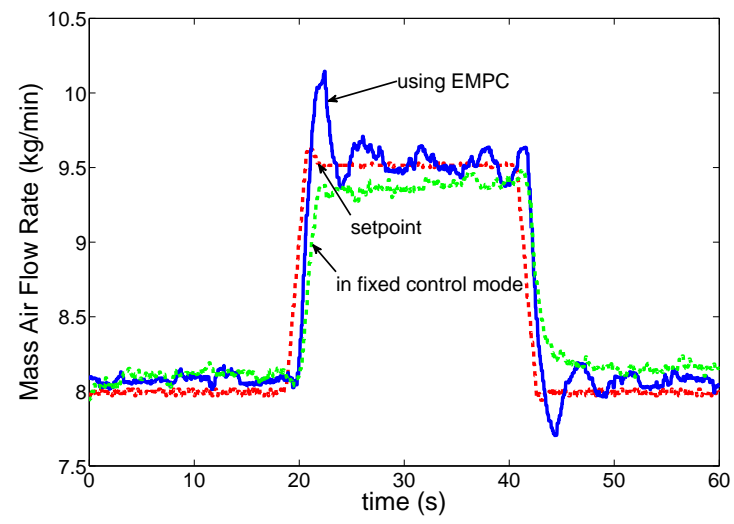

(b) $W_{c}$

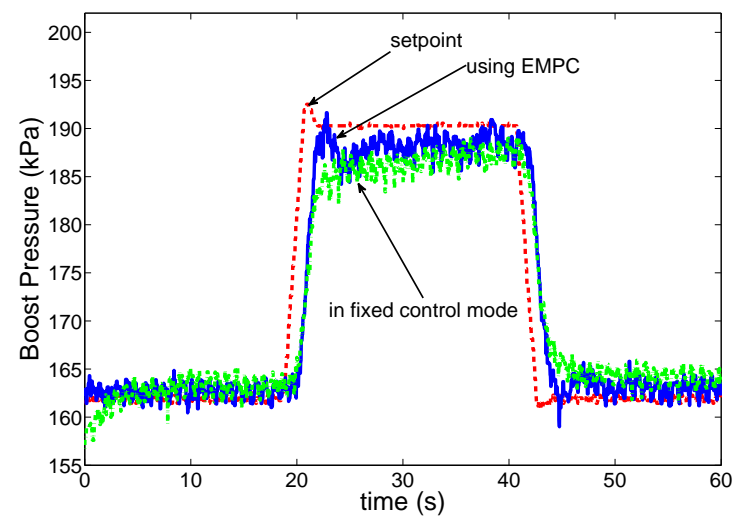

(c) $p_{\text {in }}$
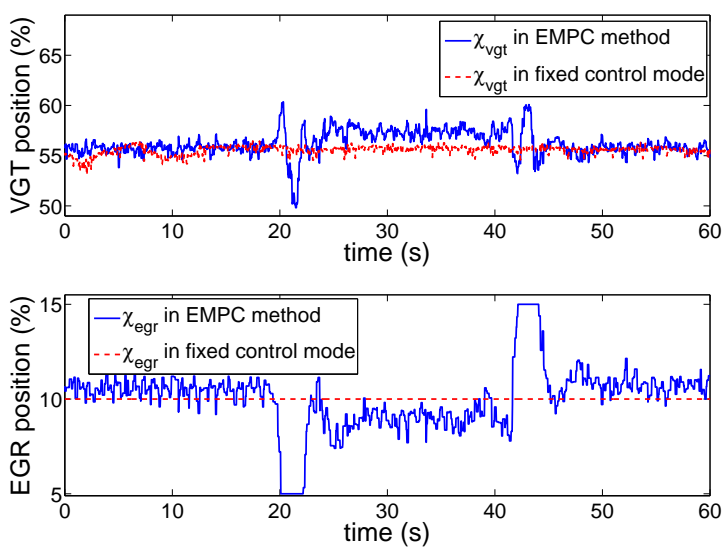

(d) Valves position

Fig. 12. Diesel engine air path control performance evaluation with $t_{\text {ramp }}=$ $2 \mathrm{~s}$ 


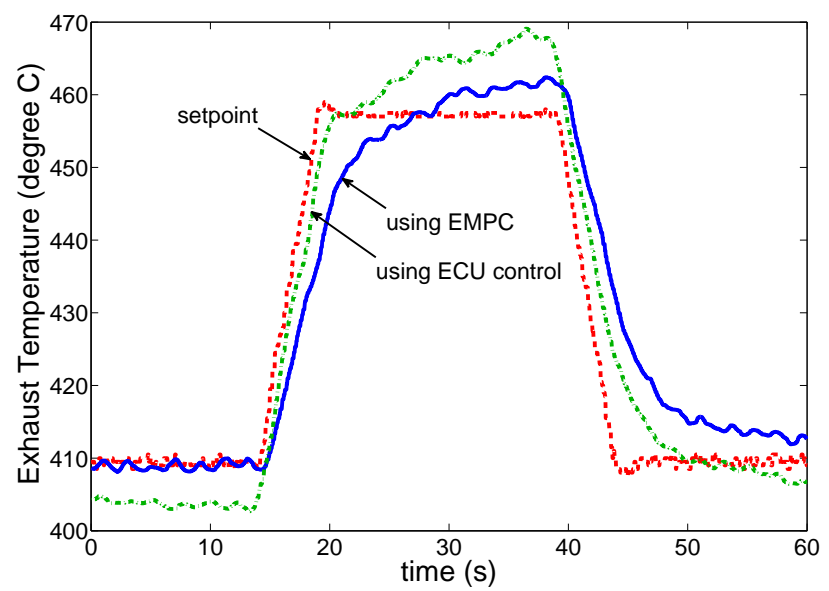

(a) $T_{e x h}$

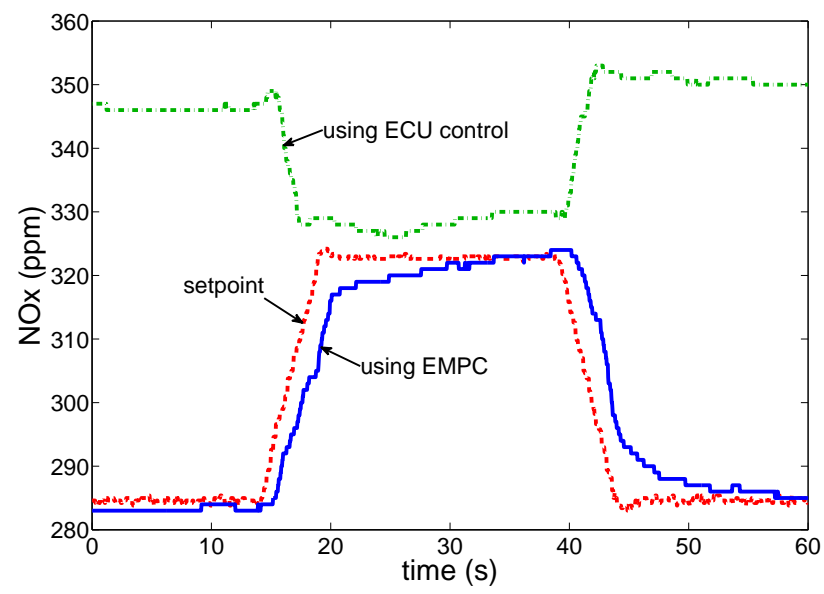

(b) $\rho_{\text {nox }}$

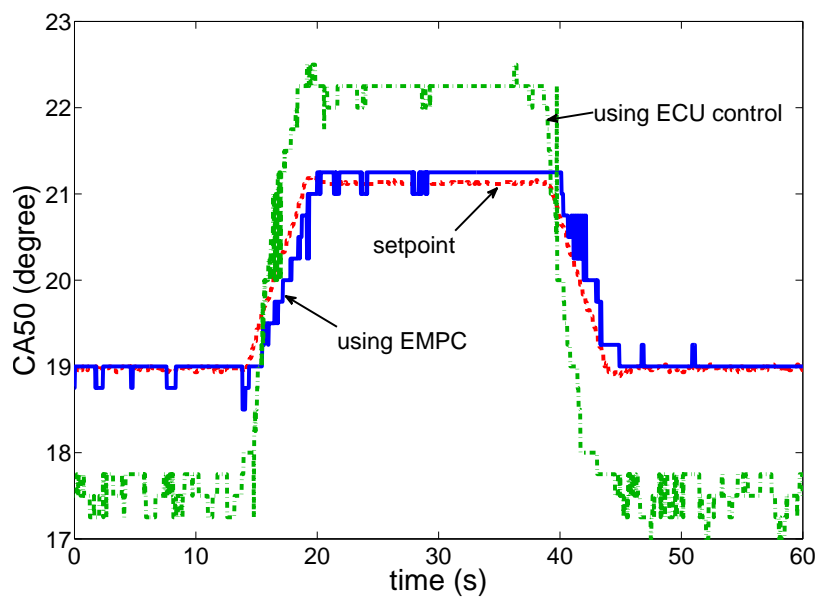

(c) $\theta_{\text {ca } 50}$

Fig. 13. Diesel engine fuel path control performance evaluation

maintain the same values as those in air path control tests. The

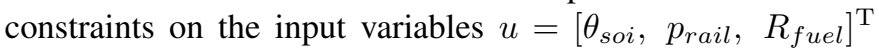
are

$u_{\min }=\left[\begin{array}{c}-4{ }^{\circ} \mathrm{CA} \mathrm{ATDC} \\ 55 \mathrm{kPa} \\ 65 \%\end{array}\right], \quad u_{\max }=\left[\begin{array}{c}10^{\circ} \mathrm{CA} \mathrm{ATDC} \\ 95 \mathrm{kPa} \\ 95 \%\end{array}\right]$.
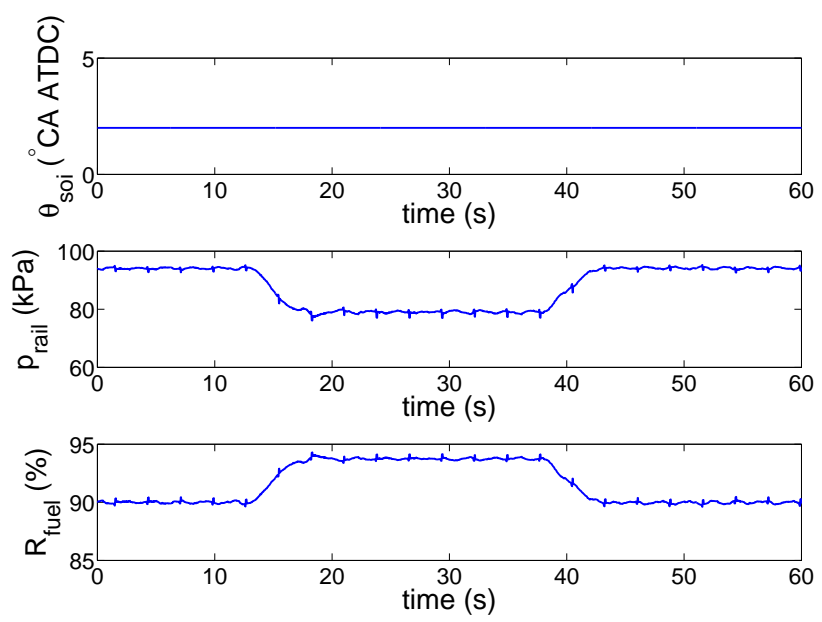

Fig. 14. Fuel path input variables tuning process in the ECU control scheme
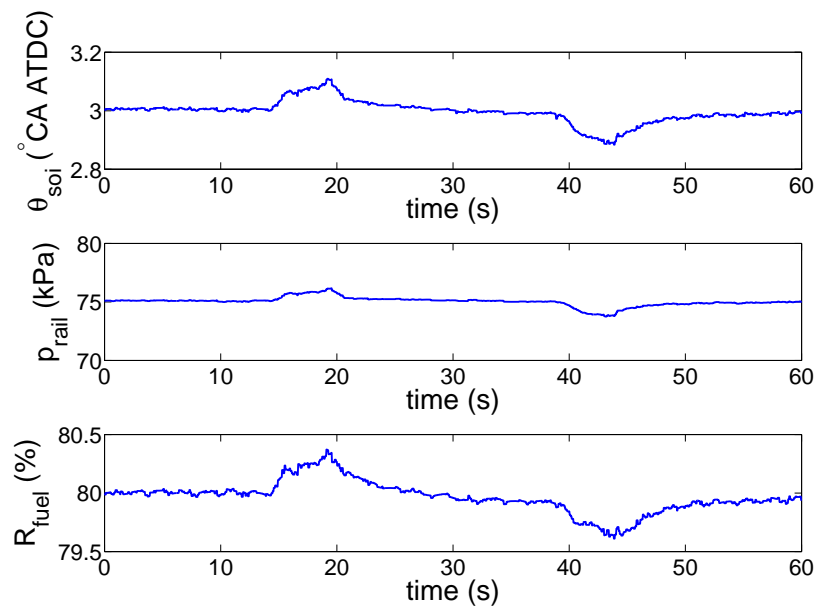

Fig. 15. Fuel path input variables tuning process in the EMPC scheme

The parameters in (12a) are set as $H_{y}=10, H_{c}=2, Q=$ $\operatorname{diag}[10,2,5]$, and $R=I_{3}$. The air path input variables are fixed at

$$
\left[\begin{array}{l}
\chi_{\text {egr }} \\
\chi_{v g t}
\end{array}\right]=\left[\begin{array}{l}
10 \% \\
55 \%
\end{array}\right] \text {. }
$$

The fuel path outputs from the embedded ECU controller and the EMPC controller are demonstrated in Fig. 13. The setpoint value of $T_{e x h}$ changes from $410{ }^{\circ} \mathrm{C}$ to $460^{\circ} \mathrm{C}$ with the ramping change of the load torque. Fig. 13(a) shows that the tracking of $T_{\text {exh }}$ in the ECU scheme is not precise, and the overshoot is rather large. In comparison, the performance of EMPC is improved due to the ability to compute the optimal control law online.

The contrast between the respective tracking performances of $\mathrm{NO}_{x}$ is shown in Fig. 13(b), which is more impressive, with its setpoint value changes from $285 \mathrm{ppm}$ to $325 \mathrm{ppm}$. Because of the $\mathrm{NO}_{x}$-PM tradeoff, it is a challenging task to guarantee precise tracking of both $\mathrm{NO}_{x}$ and $\mathrm{PM}$, simultaneously. The $\mathrm{NO}_{x}$ tracking performance in ECU scheme is very weak since the PID controller just uses the feedback output to compute the control law for the corresponding variable, ignoring the coupling between the multi-output variables. When the load torque is changed to $475 \mathrm{Nm}$, the tracking performance of 
$\mathrm{NO}_{x}$ is slightly improved, but the tracking performance in other stages is far from acceptable. The tracking performance of $\mathrm{NO}_{x}$ using the EMPC controller is much better, because the receding horizon is employed in the MPC technique. The optimal control action can be implemented on the diesel engine at every sampling instant, leading to a smaller tracking error.

The biggest advantage of the EMPC over the ECU control, in comparing the $\theta_{c a 50}$ tracking performance, is in the reduced steady state error, while the setpoint value changes from $19^{\circ}$ to $21.25^{\circ}$. This is shown in Fig. 13(c). The integrator in the PID controller was set as a reasonable value, to avoid the response lagging due to a too strong integrator according to the experimental experience. In the formulated model (11) for the EMPC controller design, integration on the step changes of the control law is included, which plays a key role in diminishing the steady state error.

Fig. 14 and Fig. 15 show the tuning process of input variables using the SISO PID controller and the EMPC controller, respectively. In Fig. 14, there is no variation in $\theta_{\text {soi }}$, while $p_{\text {rail }}$ and $R_{\text {fuel }}$ are regulated in opposite directions, responding to the change of the setpoint values. Furthermore, $P_{\text {rail }}$ and $R_{f u e l}$ are very close to the physical constraints defined above. The unexpected phenomenon indicates SISO controllers are not good choices for the high-order turbocharged diesel engines, because there is no explicit relation between manipulated variables and exhaust emission performance variables.

In Fig. $15, \theta_{\text {soi }}, p_{\text {rail }}$, and $R_{\text {fuel }}$ change in a similar way around the mean values of $3{ }^{\circ} \mathrm{CA}$ ATDC, $75 \mathrm{kPa}$, and $80 \%$, respectively. Only minor variations are introduced in response to the change on the setpoint values of the exhaust performance variables with better tracking performance. The variation in the input variables shows that EMPC is feasible in the wide operation range of the diesel engine.

\section{CONCLUSIONS}

An EMPC scheme has been proposed for the diesel engine exhaust emissions regulation. Diesel engines demonstrate strong nonlinearities so that the emission variables cannot be well controlled independently by regulating actuators independently. An EMPC controller is designed to cope with the highly nonlinear dynamics in a straight-forward way, whose robustness is guaranteed by the Kalman filter against the disturbances resulting from process and sensor noises. Comparing with the traditional MPC, the EMPC uses far fewer resources, while maintaining the identical performance as MPC. The state-space models of the diesel engine including the air path and fuel path are identified at several steady operation points, under a reasonable hypothesis. An augmented EMPC controller is formulated with the increment of control actions, such that the tracking is improved and the steady state errors are significantly diminished. Experimental results show that the proposed EMPC strategy demonstrates high precision in trajectory tracking, as well as the high robustness against the step change in load torque.

This paper has a potential reference value in the design and implementation of real-time control algorithms for turbocharged diesel engines, and in a wider range, for more industrial application fields. As a topic for future work, the disturbance compensator on the forward channel should be designed to reduce the influence of the noise on VGT and EGR actuators.

\section{REFERENCES}

[1] G. Stewart and F. Borrelli, "A model predictive control framework for industrial turbodiesel engine control," in Proceedings of the 47th IEEE Conference on Decision and Control, 2008, pp. 5704-5711.

[2] P. Langthaler and L. del Re, "Robust model predictive control of a diesel engine airpath," in Proceedings of the 17th IFAC World Congress, 2008, pp. $9485-9490$.

[3] X. Wang, H. Waschl, D. Alberer, and L. del Re, "A design framework for predictive engine control," Oil \& Gas Science and Technology, vol. 66, no. 4, pp. 599-612, 2011.

[4] M. Jankovic and I. Kolmanovsky, "Constructive Lyapunov control design for turbocharged diesel engines," IEEE Transactions on Control Systems Technology, vol. 8, no. 2, pp. 288-299, 2000.

[5] A. G. Stefanopoulou, I. Kolmanovsky, and J. S. Freudenberg, "Control of variable geometry turbocharged diesel engines for reduced emissions," IEEE Transactions on Control Systems Technology, vol. 8, no. 4, pp. 733-745, 2000.

[6] A. Plianos and R. K. Stobart, "Nonlinear airpath control of modern diesel powertrains: a fuzzy systems approach," International Journal of Systems Science, vol. 42, pp. 263-275, 2011.

[7] S. Garcia-Nieto, M. Martinez, X. Blasco, and J. Sanchis, "Nonlinear predictive control based on local model networks for air management in diesel engines," Control Engineering Practice, vol. 16, no. 12, pp. $1399-1413,2008$

[8] P. Langthaler and L. del Re, "Decentralized and multivariable designs for EGR-VGT control of a diesel engine," in Proceedings of the 2nd IFAC Workshop on Advances in Automotive Control, 1998, pp. 189-194.

[9] J. Chauvin, G. Corde, N. Petit, and P. Rouchon, "Experimental motion planning in airpath control for HCCI engine," in Proceedings of the American Control Conference, 2006, pp. 1874-1879.

[10] J. Deng, E. Winward, R. Stobart, and P. R. Desai, "Modeling techniques to support fuel path control in medium duty diesel engines," $S A E$ International, pp. 2010-01-0332, 2010.

[11] E. Winward, J. Deng, and R. Stobart, "Innovations in experimental techniques for the development of fuel path control in diesel engines," SAE International, pp. 2010-01-1132, 2010.

[12] A. Schilling, A. Amstutz, and L. Guzzella, "Model-based detection and isolation of faults due to ageing in the air and fuel paths of common-rail direct injection diesel engines equipped with a $\lambda$ and a nitrogen oxides sensor," Proceedings of the Institution of Mechanical Engineers, Part D: Journal of Automobile Engineering, vol. 222, no. 1, pp. 101-117, 2008.

[13] A. Sciarretta, M. Back, and L. Guzzella, "Optimal control of parallel hybrid electric vehicles," IEEE Transactions on Control Systems Technology, vol. 12, no. 3, pp. 352-363, 2004.

[14] J. Wahlstrom, L. Eriksson, and L. Nielsen, "EGR-VGT control and tuning for pumping work minimization and emission control," IEEE Transactions on Control Systems Technology, vol. 18, no. 4, pp. 9931003, 2010.

[15] C. C. Lin, H. Peng, J. W. Grizzle, and J. M. Kang, "Power management strategy for a parallel hybrid electric truck," IEEE Transactions on Control Systems Technology, vol. 11, no. 6, pp. 839-849, 2003.

[16] T. Maruyama, T. Shimura, A. Ejiri, Y. Ikai, and K. Shimotani, "Model predictive control applied to a diesel engine air-path system with dead time," in Proceedings of the SICE Annual Conference, 2011, pp. 26282633.

[17] F. Villarroel, J. R. Espinoza, C. A. Rojas, J. Rodriguez, M. Rivera, and D. Sbarbaro, "Multiobjective switching state selector for finite-states model predictive control based on fuzzy decision making in a matrix converter," IEEE Transactions on Industrial Electronics, vol. 60, no. 2, pp. 329-336, 2013.

[18] C. S. Lim, N. Rahim, W. P. Wooi Ping Hew, and E. Levi, "Model predictive control of a two-motor drive with five-leg-inverter supply," IEEE Transactions on Industrial Electronics, vol. 60, no. 1, pp. $54-$ 65, 2013.

[19] C. Xia, Y. Wang, and T. Shi, "Implementation of finite-state model predictive control for commutation torque ripple minimization of permanent-magnet brushless dc motor," IEEE Transactions on Industrial Electronics, vol. 60, no. 3, pp. 896 - 905, 2013. 
[20] Z. Song, C. Xia, and T. Liu, "Predictive current control of three-phase grid-connected converters with constant switching frequency for wind energy systems," IEEE Transactions on Industrial Electronics, vol. 60, no. 6, pp. 2451 - 2464, 2013.

[21] Q. Xu and Y. Li, "Micronanopositioning using model predictive output integral discrete sliding mode control," IEEE Transactions on Industrial Electronics, vol. 59, no. 2, pp. 1161 - 1170, 2012.

[22] D. C. in Model Predictive Current Control of a Three-Phase Inverter, "Cortes, p. and rodriguez, j. and silva, c. and flores, a." IEEE Transactions on Industrial Electronics, vol. 59, no. 2, pp. 1323 - 1325, 2012.

[23] Y. P. Pan and J. Wang, "Model predictive control of unknown nonlinear dynamical systems based on recurrent neural networks," IEEE Transactions on Industrial Electronics, vol. 59, no. 8, pp. 3089-3101, 2012.

[24] A. R. Neshasteriz, A. K. Sedigh, and H. Sadjadian, "Generalized predictive control and tuning of industrial processes with second order plus dead time models," Journal of Process Control, vol. 20, no. 2, pp. 63-72, 2010.

[25] A. Murilo, M. Alamir, and P. Ortner, "Multivariable control strategy based on a parameterized NMPC for a diesel engine air path," in Preceedings of the 21st International Congress of Mechanical Engineering, 2011.

[26] M. Herceg, T. Raff, R. Findeisen, and F. Allgower, "Nonlinear model predictive control of a turbocharged diesel engine," in Proceedings of the IEEE International Conference on Control Applications, 2006, pp. 1702-1707.

[27] A. Plianos, R. Stobart, and A. Achir, "Real-time adaptive predictive control of the diesel engine air-path based on fuzzy parameters estimation," SAE International, pp. 2007-01-0971, 2007.

[28] H. J. Ferreau, P. Ortner, P. Langthaler, L. del Re, and M. Diehl, "Predictive control of a real-world diesel engine using an extended online active set strategy," Annual Reviews in Control, vol. 31, no. 2, pp. 293-301, 2007.

[29] P. Ortner and L. del Re, "Predictive control of a diesel engine air path," IEEE Transactions on Control Systems Technology, vol. 15, no. 3, pp. 449-456, 2007.

[30] S. Mariethoz and M. Morari, "Explicit model-predictive control of a PWM inverter with an LCL filter," IEEE Transactions on Industrial Electronics, vol. 56, no. 2, pp. 389-399, 2009.

[31] A. G. Beccuti, S. Mariethoz, S. Cliquennois, S. Wang, and M. Morari, "Explicit model predictive control of DC-DC switched-mode power supplies with extended Kalman filtering," IEEE Transactions on Industrial Electronics, vol. 56, no. 6, pp. 1864-1874, 2009.

[32] M. Kvasnica, Real-time model predictive control via multi-parametric programming: theory and tools. Saarbrucken, Germany: VDM Verlag Dr. Muller, 2009.

[33] A. Bemporad, M. Morari, V. Dua, and E. N. Pistikopoulos, "The explicit linear quadratic regulator for constrained systems," Automatica, vol. 38, no. 1, pp. 3-20, 2002.

[34] A. Bemporad, F. Borrelli, and M. Morari, "Model predictive control based on linear programming - the explicit solution," IEEE Transactions on Automatic Control, vol. 47, no. 12, pp. 1974-1985, 2002.

[35] P. Tondel, T. A. Johansen, and A. Bemporad, "An algorithm for multi-parametric quadratic programming and explicit MPC solutions," Automatica, vol. 39, no. 3, pp. 489-497, 2003.

[36] F. Yan and J. Wang, "Air- and fuel-path coordinated control for advanced combustion mode transitions in diesel engines," in Proceedings of the American Control Conference, 2012, pp. 2890-2895.

[37] D. J. Dausen, A. G. Stefanopoulou, K. J. M., J. A. Eng, and T. W. Kuo, "A mean-value model for control of homogeneous charge compression ignition (HCCI) engines," Journal of Dynamic Systems, Measurement and Control, Transactions of the ASME, vol. 127, no. 3, pp. 355-362, 2005.

[38] E. Alfieri, A. Amstutz, and L. Guzzella, "Gain-scheduled model-based feedback control of the air/fuel ratio in diesel engines," Control Engineering Practice, vol. 17, no. 12, pp. 1417-1425, 2009.

[39] P. Ortner, P. Langthaler, O. J. V. Garcia, and L. del Re, "MPC for a diesel engine air path using an explicit approach for constraint systems," in Proceedings of the IEEE International Conference on Control Applications, 2006, pp. 1696-1701.

[40] A. Hakansson, "CA50 estimation on HCCI engine using engine speed variations," Ph.D. dissertation, 2007.

[41] M. S. Bazaraa, H. D. Sherali, and C. M. Shetty, Nonlinear programming - theory and algorithms, 2nd ed. New York, USA: Wiley, 1993.

[42] P. Tondel, T. A. Johansen, and A. Bemporad, "Evalutaion of piecewise affine control via binary search tree," Automatica, vol. 39, no. 5, pp. 945-950, 2003.
[43] F. Auger, M. Hilairet, J. Guerrero, E. Monmasson, T. OrlowskaKowalska, and S. Katsura, "Industrial applications of the kalman filter: A review," IEEE Transactions on Industrial Electronics, vol. 60, no. 12, pp. $5458-5471,2013$.

[44] S. Y. Chen, "Kalman filter for robot vision: A survey," IEEE Transactions on Industrial Electronics, vol. 59, no. 11, pp. 4409-4420, 2012.

[45] J. M. Kanieski, R. Cardoso, H. Pinheiro, and H. A. Grundling, "Kalman filter-based control system for power quality conditioning devices," IEEE Transactions on Industrial Electronics, vol. 60, no. 11, pp. 5214 - 5227, 2013. 